LICENÇA CC BY: Artigo distribuído sob os termos Creative Commons, permite uso e distribuição irrestrita em qualquer meio desde que o autor credite a fonte original.

\title{
PESQUISA EM EDUCAÇÃO: EDUCAÇÃO COMPARADA A PARTIR DE ESTUDOS DE NÓVOA E FERREIRA
}

RESEARCH ON EDUCATION: COMPARATIVE EDUCATION FROM NÓVOA AND FERREIRA STUDIES

INVESTIGACIÓN EN EDUCACIÓN: EDUCACIÓN COMPARADA A PARTIR DE ESTUDIOS DE NÓVOA Y FERREIRA

Dinora Tereza Zucchetti ${ }^{1}$

'Doutora em Educação pela UFRGS. Docente do Programa de Pós-Graduação em Diversidade Cultural e Inclusão Social da Universidade Feevale (FEEVALE), Novo

Hamburgo, RS, Brasil.

Resumo: O artigo de revisão bibliográfica versa sobre a pesquisa Educação Comparada, apresentando-a como campo de conhecimento que contribui para a grande área da Educação. Fá-lo a partir de estudos de Nóvoa e Ferreira, professores da Universidade de Coimbra, evidenciando a dimensão problematizadora do conhecimento que considera novas perspectivas para o tempo e o espaço em educação. Com a Educação Comparada, a emergência de um Outro, sujeito de aprendizagem que, não somente, se inscreve numa realidade, mas emerge como parte de uma filiação disciplinar, cultural e ideológica (FERREIRA, 2014). Na busca por dar a compreender a Educação Comparada, na perspectiva dos autores, apresentam-se a problemática, os objetivos e a metodologia de uma investigação sobre educação integral, em curso, no estado do Rio Grande do Sul.

Palavras Chave: Educação; Educação Comparada; Pesquisa.

Abstract: The literature review article deals with Comparative Education research, a field of knowledge that contributes to the large area of Education. The basis of this area of knowledge derive from Nóvoa e Ferreira studies, professors at Coimbra University, highlighting the problematizing dimension of knowledge that considers new perspectives for time and space in education. Through Comparative Education, the emergence of an Other learning subject, which not only fits into a reality, but emerges as part of a disciplinary, cultural and ideological affiliation (FERREIRA, 2014). In the search for a better understanding of Comparative Education, from the authors' perspective, we present the problematic, the objectives and the methodology of an ongoing investigation about integral education in the state of Rio Grande do Sul.

Key Words: Education; Comparative Education; Research.

Resumen: El artículo de revisión de literatura trata sobre la investigación Educación Comparada, presentándola como un campo de conocimiento que contribuye a la gran área de la Educación. Ocurre hasta los estudios de Nóvoa y Ferreira, profesores de la Universidad de Coimbra. El texto destaca la dimensión que problematiza el conocimiento que considera nuevas perspectivas para el tiempo y el espacio. Con la Educación Comparada la emergencia de un Otro, sujeto de aprendizaje, que no solo se inscribe en una realidad, pero emerge como 
parte de una filiación disciplinaria, cultural e ideológica (FERRERIA, 2014). En la búsqueda por una mejor comprensión la Educación Comparada, desde la mirada de los autores presentase la problematización, los objetivos y la metodología de una investigación en curso sobre la educación integral en el estado del Rio Grande do Sul.

Palabras Claves: Educación; Educación Comparada; Investigación.

\section{Introdução}

A pesquisa Educação Comparada como área de estudo e enquanto método à maneira como tem sido abordada, a exemplo de Martin Carnoy, António Gomes Ferreira, António Nóvoa, Jürgen Schriewer, em pouco se associa à sua vertente mais positivista. Segundo Nóvoa (s.a.) a história da educação centrou-se em concepções demasiado rígidas de tempo, espaço, contexto, na perspectiva de uma funcionalidade do sistema, no caso o educativo. Essa modalidade, segundo o autor, veio historicamente sendo utilizada, grosso modo, para comparar, por exemplo, sistemas de ensino de diferentes países com vista a encontrar soluções ou, ao menos, a melhor solução para os 'mesmos' problemas educativos, na perspectiva dos rankings internacionais. Sob a retórica da cientificidade, enfatiza o autor, foi possível dissimular, entre outros, as dimensões ideológicas presentes nas comparações de ranqueamentos.

Uma nova versão para os estudos sobre a pesquisa Educação Comparada que agrega uma renovação epistemológica e metodológica, ainda segundo Nóvoa (FRANCO, PEREIRA E DALLABRIDA, 2009), parte de um pensamento histórico-comparado na área da educação. Para melhor exemplificar e demonstrar a atualidade dos estudos, em 'Ilusões e desilusões sobre a Educação Comparada: política e reconhecimento', Nóvoa $(2017)^{1}$ historiciza, brevemente, o percurso desta área do conhecimento citando, inicialmente, Jullien de Paris (1817). A ele atribui o uso de tábuas comparativas para relacionar, comparar e deduzir princípios e regras estabelecendo relações entre a Anatomia Comparada e a Educação Comparada, em uma perspectiva mais descritiva, mais ou menos positivista e primando por uma diretriz analítica, sempre linear.

Apresenta, na sequência, também de modo breve, o modelo escolar a partir da Exposição Universal de Paris, de 1867, onde desenha-se o novíssimo catálogo da modernização escolar enquanto uma matriz para avaliar a educação de diferentes países europeus, destacando-se a dimensão imaginativa da comparação. As imagens apresentadas na Exposição revelavam o espetáculo das grandes invenções ocorridas na segunda metade do século XIX e como passaram a influenciar uma sociedade de massas, na qual a educação teve papel fundamental.

Numa terceira geração, por assim dizer, a pesquisa em Educação Comparada ganhou destaque a partir de duas abordagens que remetiam às origens desta vertente/campo de estudo, contudo, elevando-se uma visão mais crítica. Na primeira, a comparação dos 
sistemas de educação e saúde é realizada a partir de Durkhein (1917) em contraposição a proposta por Jullien de Paris. Na segunda, a composição da ciência pelos comparativos científicos nos estudos dos tipos genéricos em educação e o princípio de causalidade são defendidas pela sociologia durkheimiana, desde onde refuta-se a comparação por imagens defendida pela Exposição Universal de Paris².

Por fim, Nóvoa (2017) refere-se à criação da International Association for the Evaluation of Educational Achievement - IEA, no ano de 1967, aludindo aos grandes dispositivos de avaliação de alunos na busca por resultados positivos. Nessa quarta geração, a Educação Comparada tem forte caráter prescritivo com o uso de métricas comparativistas a exemplo das avaliações realizadas pelo Programme for International Student Assessment - PISA. A lógica em que o desenvolvimento econômico é tido como o grande objetivo da educação e da aprendizagem tem conformado uma ideia hegemônica, a de que o capital humano viceja sobre tudo.

Partindo desta retomada histórica esse artigo propõe uma revisão bibliográfica de estudos realizados pelos professores António Nóvoa e António Gomes Ferreira, ambos catedráticos da Universidade de Coimbra - Portugal, a fim de apresentar uma nova geração (quinta geração) de saberes para a Educação Comparada. A partir dos dois pesquisadores nos vemos mediante uma área de estudo que serve para produzir inteligibilidades sobre determinadas realidades em educação, em seu sentido lato senso. De outra parte, com o objetivo de destacar o uso da pesquisa Educação Comparada, de tipo intranacional, enquanto metodologia para produzir investigações com maior efetividade social apresentamos, mesmo que de modo breve, fragmentos de uma investigação ativa no campo da educação integral.

\section{A Educação Comparada em perspectiva.}

Desde onde centra-se o interesse deste estudo enfatiza-se a Educação Comparada como área ou disciplina que dá acesso às compreensões: como e porquê, uma situação se apresenta de um determinado modo e não de outro, em diferentes contextos. Tal problematização pressupõe a realização de um tipo de estudo em que se visualize, entre outros, dados históricos, diagnósticos sociais, características de um evento/realidade/ empreendimento educativo dado. Para tanto, está em causa uma série de categorias temáticas, entre elas: universalidade, dialogia, alteridade, participação, política, espacialidade, historicidade e a complexidade, própria de áreas de conhecimento que transversalizam a educação, a exemplo, da história, da sociologia e da filosofia.

O envolvimento de diferentes atores sociais, a compreensão das condições materiais para que um determinado fenômeno emerja e/ou uma realidade se consolide são questões atinentes aos estudos da Educação Comparada em Nóvoa e Ferreira, nossos autores de referência. Nesse cenário nos interessa, sobremaneira, a vertente da 
Educação Comparada na sua perspectiva compreensiva e socio-histórica. Contexto em que Ferreira $(2008 ; 2014)$ a afirma enquanto modalidade investigativa de abordagem sistêmica que considera a aprendizagem, o Outro sujeito da investigação, a realidade complexa, o desenvolvimento tecnológico, a formação da consciência, as mobilizações com capacidade de organização política, quando sustentadas na teoria crítica. Questões que, por aproximação, tendem a se fazer presentes também nos estudos sobre Educação Comparada realizados por Nóvoa. Cada um deles, separadamente e/ ou em conjunto, ou ainda em diálogo com interlocutores é estudado, na sequência desse texto, de modo a contribuir para o objetivo atribuído a esta revisão, qual seja, a Educação Comparada enquanto área de conhecimento no campo da educação e sua contribuição para a pesquisa científica.

\section{António Nóvoa}

Segundo Nóvoa, em consonância com os estudos realizados por Schriewer (2018) e António Gomes Ferreira (2008, 2014), a Educação Comparada em uma abordagem compreensiva precisa ser entendida no sentido de ultrapassar os limites dos estudos mais tradicionais e positivistas. Para tanto, busca por compreendê-la a partir da noção de comparação enquanto exercício crítico "que permita criar categorias férteis na apreensão das peculiaridades dos processos de apropriação dos saberes e da intervenção prática no campo educacional" (NÓVOA E CATANI, 2000, p. 1).

Compete a Nóvoa e Catani (2000) resgatar a obra escrita por Nóvoa (1998) quando propunha um esforço de comparação para o reconhecimento da indissolubilidade em compreendero Outro, nãocomo um arranjo sistematizado de fatos/dados individualizados, mas como uma conjunção de sentidos que diferentes comunidades atribuem às ações humanas. A fim e a cabo, tais sentidos servem para consolidar maneiras de pensar e agir que são evidenciadas pela investigação científica e seus saberes, em especial, nas ciências da educação.

Relacionando a Educação Comparada à história da educação Nóvoa, em entrevista fornecida para Franco, Pereira e Dallabrida (2009, p. 6), refere que ambas, por muito tempo, ficaram "enclausuradas numa concepção excessivamente cronológica do tempo, muito positivista", reduzidas à comparação de práticas e resultados de sistemas educativos entre estados nações. Não compartilhando desta concepção, Nóvoa advoga que a verdadeira comparação deve "romper com conceitos demasiado geográficos e limitados, sobretudo com o que foi a Educação Comparada [...] baseada por perguntas diretivas no sentido de saber, por exemplo, 'o que é que Portugal pode aprender com as reformas educativas espanholas'" (FRANCO, PEREIRA E DALLABRIDA, 2009, p. 7).

Primando pelas diferenças - não por generalizações - a Educação Comparada não está, em absoluto, em busca de um tipo ideal de cada região, afirma Nóvoa, na mesma 
entrevista. É o ponto de vista histórico, a inteligibilidade, os sentidos que são atribuídos a um conjunto de realidades o que se busca encontrar, prioritariamente, enquanto achados investigativos. Nessa perspectiva, a pesquisa Educação Comparada se apresenta, por um lado, como uma epistemologia, por outro, enquanto metodologia investigativa.

Na primeira alternativa, de caráter epistemológico, o sentido emerge da conjunção entre a política e o conhecimento, não enquanto saberes de especialistas, mas como experiências necessárias ao debate público na defesa por "um espaço público de discussão e deliberação que seja ao mesmo tempo, um espaço de padrão do comum" (NÓVOA, 2017, p. 15). Ao defender uma esfera pública de ação, retoma autores como George Agamben (2007) enquanto resposta ao consumo e ao espetáculo, ambos potencializados pela revolução digital e pelas redes sociais e Hanna Arendt (1995) no que tange a fragmentação do homem moderno. "Para mim, como para Hanna Arendt ou Giorgio Agamben, o comum não é um lugar de identidade, de similitude, mas, bem pelo contrário, o trabalho e a reflexão em comum a partir das nossas diversidades e diferenças", afirma Nóvoa (2017, p. 27).

Busca em John Dewey (1979), por sua vez, a inspiração para afirmar que na pesquisa Educação Comparada a importância da comunicabilidade enquanto experiência democrática, por vezes, valora mais do que o próprio conceito de comunidade. Segundo Dewey (1979), nem todas as relações são sociais, somente serão assim consideradas aquelas que puderem ser comunicadas, o que atribui à comunicação semelhança a arte. Isto é, o artista cria a arte, o produto artístico, entretanto, a obra de arte é o que o artista provoca em quem a experimenta (DEWEY, 2019). No seu oposto, quando banalizadas - comunicação e arte - não são consideradas educativas e, portanto, não se sustentam enquanto valor social.

Com base nessas aproximações Nóvoa (2017), reafirma a Educação Comparada enquanto contributo fundamental no combate à fragmentação do pensamento na busca pelo que é educativo nas relações sociais e comunicacionais e o que isto representa em comum. Todavia, a Educação Comparada, também, se interessa pelo educativo no que as experiências divergem. Ressalta, para tanto, alguns desafios a fim de investir na Educação Comparada enquanto campo educacional: a reconstrução e revalorização do espaço público de discussão e de deliberação da produção do comum; a reapropriação da temática da educação, por parte dos cidadãos; a relevância do entendimento, numa determinada circunstância, para a tomada de decisão daquilo que é pertinente ao ato de educar.

Para tanto, o autor chama a atenção:

Não seremos capazes de problematizar os fenómenos educativos se nos fecharmos nos espaços tradicionais de comparação. Dentro de cada país, existem muitos países, muitas realidades. Dentro de cada cidade, existem muitas cidades. Dentro de cada bairro, dentro de cada lugar. Se não reconhecermos as diferentes espacialidades que existem no mesmo espaço, as diferentes temporalidades que existem no nosso tempo, dificilmente poderemos avançar para novas formas de pensar (NÓVOA, 2017, p. 25). 
Em alinhamento ao exposto, a relação da Educação Comparada na perspectiva metodológica (a segunda alternativa) apresenta suas principais contribuições enquanto uma derivação do seu sentido entre a política e o conhecimento, próprios da sua dimensão epistemológica (primeira alternativa). Isto é, em relação a educação escolar, por exemplo, Nóvoa afirma em Franco, Pereira, Dallabrida (2009, p. 10) que: "a escola não resolve nenhum problema da sociedade, a sociedade é que tem que resolver os problemas da sociedade. Não cabe à escola o papel de regeneradora da sociedade ou do Homem". Esta concepção gera deslocamentos importantes na perspectiva das investigações sobre a educação por produzir pesquisas sobre o ensino em direção à cultura do conhecimento. Isso implica, ao ver do autor, que o conhecer, o aprender e a apropriação do conhecimento devem ser apropriados pelos sujeitos da investigação.

Estas questões partem de uma consideração fundante, qual seja, a pesquisa Educação Comparada se apresenta como um método investigativo que objetiva abrir problemáticas na busca por compreender diferenças. Para tanto necessita escapar de meras medições, características dos estudos mais positivistas. Há algo no meio, um nível intermediário, um intermezzo, afirma Nóvoa (2017), referindo-se à necessidade de avançar para além de pesquisas que buscam, meramente, demonstrar o que é o melhor e/ou de que tudo é homogêneo no sistema mundial. Para tanto, defende uma pesquisa Educação Comparada menos calcada na dimensão geográfica das nações e mais na importância das localizações, enquanto manifestações culturais e históricas.

Entre os métodos, nessa perspectiva, há para Nóvoa (2017) três importantes gestos: o gesto do distanciamento, o gesto da intercessão e o gesto da comunicação, todos imprescindíveis à prática investigativa. Tais gestos, na sua necessidade de aprofundamento, nos remetem, entre outros autores, a Freire e sua referência ao "distanciamento" epistemológico. Categoria que, embora, tratada em várias obras vem melhor explicitada na Pedagogia da Autonomia (1979) ao ser definida enquanto exercício do pensamento sobre a prática, momento fundamental de reflexão crítica e não ingênua sobre a ação, onde a teoria necessita aproximar-se, ao máximo, da sua própria rigorosidade.

Em relação ao gesto da intercessão, Nóvoa (2017) busca em diálogo com Deleuze (1992), por aquilo que se passa 'entre'. Assim, o que realmente importa não está no que se repete (presente nos modelos clássicos de pesquisas comparativas), mas nas linhas fugidias, no que falseia, no que silencia, no que falta. Isto é compreendido por Deleuze (1992, p. 157) como sendo os intercessores, porque uma verdade, segundo o autor, "não é algo preexistente, a ser descoberto, mas que deve ser criado em cada domínio, é evidente nas ciências, por exemplo". Os intercessores são atos de interferência e de criação observados na ciência, pela função do agir; na arte, pelo que agrega por afetar; na Filosofia, quando pela via dos conceitos permite o perceber. pessoas [...] mas também coisas, plantas e até animais como em Castañeda. [...] Se não formarmos 
uma série, mesmo que completamente imaginária estamos perdidos. [...] Felix Guattari e eu somos intercessores um do outro. (DELEUZE, 1992, p. 156).

Sobre o terceiro gesto, a comunicação, é entendida, por exemplo, como o ato que vai publicizar, comunicar os resultados de uma investigação. Assim que interessa menos a comparação das coisas com as coisas e mais os problemas que emergem entre si. Por exemplo, a busca por tornar algo que comunica dando visibilidade à diferentes posições e maneiras de pensar em uma sociedade em rede, facilita, mas também congela, perturba, cria vácuos o que, por sua vez, demandam por uma ética do comum. Essa, no nosso entendimento, pode ser representada a partir do apelo do Rosto, tal qual presente nos estudos de Lévinas (2005).

O Rosto, como imposição de uma radicalidade da alteridade, requer gestos de comunicação que se dão pela diferença, pela presença do Outro. Assim, ao contrário do que se repete, o exercício da Educação Comparada visa buscar o singular para poder compreender.

Por fim, o Nóvoa (2017) chama a atenção para a dimensão da relação espaçotempo nas investigações. Afirma que o estado nação não perde centralidade nas pesquisas de Educação Comparada, contudo, ganham notoriedade os estudos locais e globais desde a micro comparação até a transnacionalização. Nessas, e a cada uma, a necessidade de reunir a política, a ciência e a democracia em um raciocínio que une o local e o global, seus fluxos, comunicações, hibridismo, redes, conexões, fluidez, flutuações. Assim que, também, não há comparação possível sem a compreensão histórica. Por isso, a importância da dimensão temporal presente nas camadas do tempo, desde onde faz-se necessário incursionar para a largura e para a espessura; cria a ideia de fio (do tempo) que se entrelaça em muito fios, produzindo uma espécie de corda (NÓVOA, 2017).

Retomando a ideia de inacabamento presente em Freire (1993) é que pensamos contribuir, no sentido de compreender as dimensões apresentadas por Nóvoa, em relação à Educação Comparada, onde nenhum conceito, nenhuma realidade, nenhuma experiência, isoladamente, é capaz de fazer reverberar a natureza criadora do humano e, também, capaz de apreendê-la (TROMBETA; TROMBETA, 2008). Nessa perspectiva, recorremos, também, a Dewey (1979) para quem a educação é um método científico que permite ao homem compreender o mundo, significá-lo, produzindo inteligências através do conhecimento. É Dewey (1979, p. 23) que, nesse sentido, nos ajuda a perguntar: o que faz produzir novas pesquisas? De imediato ele responde a partir da ideia do continnum existencial, princípio aplicado para "discriminar entre experiência de valor educativo e experiência sem tal valor". A partir desse princípio, segundo o autor, é possível reiterar a importância do espaço-tempo, da historicidade, da natureza dos problemas quando, por meio de estudos críticos e associado a um corpo de conhecimento, produz-se vida inteligente; daí a necessidade de sempre investir na ciência e na tecnologia na perspectiva do seu inacabamento. 


\section{António Gomes Ferreira}

A educação, como campo de ação complexo, além da dificuldade de deixar apreender-se não se reduz a simples ciência. Sua inteligibilidade, afirma Ferreira (2008), demanda por compreender assuntos diversificados, demonstrados a partir de conhecimentos e abordagens pluridisciplinares, tendo em vista a urgência de posições consistentes por parte de grupos de pesquisas e universidades. A combinação de "desenvolvimento tecnológico, com a consciência e a mobilização ideológica com a capacidade de organização política" (p. 137) cria as condições para estudos a partir de abordagens sistêmicas, de aprendizagens compreensivas, que fazem dialogar disciplinas como a Filosofia, História e Ciências Sociais. Essas são algumas das premissas que, segundo Ferreira, sustentam os estudos sobre a pesquisa Educação Comparada enquanto a diferencia da comparação experimental, estatística e de tábua, referindo-se que essas sempre existiram.

A perspectiva compreensiva, para o autor, como desígnio da Educação Comparada está a incitar a democratização dos saberes e dos resultados investigativos. Para tanto, essa perspectiva:

não se compadece com autoritarismos e sectarismos, antes exige uma atitude de forte empenho
intelectual na verificação da legitimidade do conhecimento anteriormente produzido e na colocação
de novas questões ou na utilização de outros métodos ou outras técnicas de investigação. [...] Ela
vai além do tratamento da informação e do cotejar dos dados, implicando a integração de uma
capacidade analítica da realidade de modo a reconstruir um saber que contribua para a elucidação das
dinâmicas educativas. A aprendizagem compreensiva é integradora e articuladora de conhecimentos,
desenha-se processualmente, dando sentido a informações variadas, quer consolidando-se, quer
alterando-se (FERREIRA, 2014, p. 225).

A Educação Comparada possui, para o autor, uma lógica social que se manifesta a partir de duas dimensões: uma histórica e outra comparada. Ambas se separam somente do ponto de vista didático, uma vez que buscam ver reagir uma mesma realidade. Para compreender o fato histórico, o autor propõe ampliar as perguntas que versam sobre o que somos e porque somos o que somos, para além das possibilidades de evolução de algo. Na perspectiva da comparação sugere, ainda, indagar questões da ordem do tempo do ato educativo - percurso educativo - num e noutro espaço e referentes a pressupostos da vulgarização de certos discursos que, em geral, são, notadamente, hegemônicos (FERREIRA, 2008).

No que tangue aos sujeitos de pesquisas em Educação Comparada, Ferreira (2014, p. 224) afirma que "grupos sociais bem definidos, gente que sentiu de algum modo formas de discriminação, gente que sentiu dificuldades de sucesso escolar, gente que resistiu à escola, gente de várias regiões dum mundo muito diversificado" são informantes de alta qualidade. Contudo, o Outro da pesquisa comparada nem sempre é o sujeito inscrito no estudo, mas pode ser a cultura, as comunidades, as instituições, as disciplinas, as ideologias, entre outros. O que, então, define este Outro? O que o define é como "se fizeram e estão fazendo, se pensaram e se pensam" (op. cit. p. 225), buscando por alcançar um pensamento coeso. 
Assim, para Ferreira (2014), o Outro é, também, a outra realidade da educação, aquilo e aqueles que escapam do discurso hegemônico e do pensamento predominante. A Educação Comparada nessa perspectiva é fundamental para que

o Outro seja compreensível em si, em função de suas políticas e das práticas educativas que o (em) formam, devemos valorizar a importância da comparação como condição fundamental da Educação Comparada para colocar a esta a exigência de buscar inteligibilidades não definidas aprioristicamente pelos poderes instituídos (FERREIRA, 2014, p. 221/222).

O exercício intelectual quando associado à complexidade do contexto social, cultural e político, pode produzir novas narrativas, propondo novas questões de pesquisas. Não se trata de abandonar o interesse "sobre os que vão à escola, [mas] também debruçar-se sobre os problemas que prejudicam o acesso à mesma" (FERREIRA, 2014, p. 224). Assim, não interessa, tão somente, a tecnologia pericial da educação, mas o investimento no esclarecimento e na apropriação de novos saberes pelos envolvidos no estudo. Não há dúvida de que estamos mediante a necessidade da transparência em pesquisa o que, em tese, remete aos pressupostos da democracia.

Desde esta compreensão ousamos relacionar as metodologias da pesquisa ação e da pesquisa participante como 'parceiras', por assim dizer, desta modalidade de estudo epistemo-investigativo. $E$, nessa perspectiva, cabe destacar a importância do diálogo enquanto estratégia (metodológica) impulsionadora do pensar crítico problematizador, imprescindível à libertação humana e fundamental à Educação Comparada. A dialogicidade implica, entre outros, o comunicar e o esperançar de um novo mundo, o que demanda por uma coerência metodológica de convicção político-filosófica. Essa relação se faz presente nos estudos de Ferreira quando enfatiza a pesquisa Educação Comparada com vistas ao desenvolvimento social e o nexo com a transparência, o diálogo e a participação, enquanto categorias essenciais à prática investigativa nessa perspectiva.

No que tange à metodológica da Educação Comparada propriamente dita, Fraga (2008) apresenta um estudo síntese sobre o modo como Ferreira, no conjunto da sua obra, descreve as fases do método comparativo, classificando-as como pré-descritiva, descritiva e comparativa.

Na fase pré-descritiva a atenção dever recair, primeiramente, sobre a identificação do problema. Isto implica um primeiro contato com o campo empírico perguntando sobre: qual é a necessidade de uma pesquisa aprofundada sobre um determinado tema. Na sequência, a elaboração de hipóteses é utilizada para facilitar a delimitação da investigação, sendo que essa delimitação deve mirar o objeto de estudo e os conceitos sistematizados, considerando-os enquanto expressão da realidade a ser investigada. Neste caso, com a licença do autor, vamos denominar tais conceitos definidos a priori, como categorias temáticas. Isso corresponde, no nosso entendimento, ao conjunto de termos presentes na investigação em si, na problemática e, principalmente, em estudos já realizados e que se acessa para contextualizar e aprofundar investigações através de 
revisões bibliográficas, por exemplo. No que tange a metodologia é fundamental, antes de avançar na investigação em Educação Comparada, verificar se há fontes documentais secundária suficientes indagando, inclusive, sobre a confiabilidade delas. Isto se deve a necessidade de um estudo histórico contextual, exaustivo, na perspectiva da comparação.

Nessa fase de delimitação do estudo é definido o tipo de comparação a ser realizado, dado o objeto de investigação e a problemática demarcada. A comparação pode ser de tipo internacional - entre Estados e Nações - ou intranacional, compreendida pela definição de unidades geográficas, espaciais, culturais, étnicas, econômicas, políticas, setoriais e institucionais. Por tanto, é possível comparar bairro/ cidade, bairros entre si, escolas entre si, por exemplo. É necessário, ainda, definir as unidades de análises, os fluxos e as (r)evoluções dos campos de pesquisa buscando por relações. Quando um fenômeno educativo surge e/ou se consolida é necessário considerar as condições especificas de cada espaço, território, para tal evidência; as condições materiais para que algo ocorra devem evidenciar os percursos históricos, educacionais e as possibilidades para a evolução de um fenômeno social. A exemplo: (in) sucesso escolar e prevalência de violência no bairro, participação na escola e presença de redes de proteção intersetoriais com a participação de usuários, impactos sobre a escolarização e a participação social de jovens do sexo feminino e incidência de gravidez na adolescência, continuidades de estudos na passagem do ensino fundamental para o médio e a presença ou não de escolas de ensino médio no território constituem comparações/questionamentos realizadas na relação entre escolas e territórios e escolas entre $\mathrm{si}^{3}$.

A fase descritiva, geralmente, é que toma mais tempo da investigação devendo observar, entre outros: a pertinência dos dados coletados e a importância de coadunar dados qualitativos e quantitativos na busca por compreensões mais consistentes. Importante ressaltar que nesta fase as comparações demandam por um paralelismo, por exemplo, a analise deverá recair sobre os mesmos documentos das escolas - os PPPs, regulamentações estadual ou municipal, aproveitamento escolar, indicadores sociais e econômicos, etc..

Aqui são realizadas as coletas de dados primários com a elaboração e aplicação de questionários, entrevistas, cujos roteiros devem emergir dos dados da fase pré-descritiva. Observações e relatos em diários de campo são recursos metodológicos importantes. Essa fase possui caráter descritivo-analítico, nela ocorre a interpretação de dados socio-históricos, formação, econômicos, das entrevistas e observações, entre outros, visando os resultados da investigação. Importante ressaltar que as fases descritiva e pré-descritiva se fundem nessa etapa da investigação.

A fase comparativa, por sua vez, é aquela em que se examina, com rigor, as semelhanças e diferenças entre os dados, no sentido de construir a comparação em múltiplos sentidos. É possível, a partir deste momento, construir mapas comparativos 
inter e entrepares rumando no sentido de apresentar os resultados da investigação. Contudo, alerta Ferreira (2008), mesmo que se respeitando as três fases da investigação, mas, somente, centrando-se no método comparativo não é possível compreender nenhum processo educativo; isto é, a comparação pressupõe uma episteme.

A episteme da educação comparada, segundo Ferreira (2008), faz verter ao problema de pesquisa e, ao mesmo tempo, permite verificar sua relação com dimensões de natureza econômica, política, social, cultural, buscando por um ecletismo interpretativo desde onde se entrecruzam saberes multirreferenciais e plurimetodológicos, afastandose dos clássicos parâmetros de semelhanças e diferenças.

Como resultados das investigações que tomam como base a Educação Comparada, Ferreira (2014) destaca, sobremaneira, a emergência de uma aprendizagem compreensiva o que, segundo o autor, é muito mais do que coletar dados, tratar informações, cotejar resultados e apresentá-los à comunidade científica. Os achados investigativos, nesta perspectiva, reconstroem saberes que, por sua vez, elucidam dinâmicas educativas, integram, articulam conhecimentos, democratizam saberes como modo e resultado; mesmo assim, não produzem verdades infalíveis, afirma o estudioso.

\section{A Educação Comparada na investigação sobre educação integral e o desenvolvimento social em escolas do RS}

Não há dúvida que estamos mediante um tempo dominado por dissensos sobre como devemos olhar para a educação e para a escola. Pela educação se ambiciona a transformação política que não depende dela e da escola se espera a superação da desigualdade social que não está ao seu alcance. Educar é mais amplo e não coincide com a escola, o que não significa que esta não deva ser organizada em função da orientação conceitual daquela, assim como aquela não pode ser indiferente ao projeto societal, politicamente possível, presente nas instituições escolares (ZUCCHETTI e FERREIRA, 2019).

Contudo, mesmo diante destes paradoxos a escola tem se mostrado "mais adequada que qualquer outra instituição às exigências de formação requeridas por uma sociedade cada vez mais marcada por uma dinâmica econômica capitalista e/ou por uma burocracia administrativa cada vez mais controladora e sofisticada" (FERREIRA, 2005, p. 179), porque oferece a instrução que assegura o saber instrumental exigido a uma sociedade de excedentes. Por outro lado, também a escola assegura a consolidação de uma ideologia que volta os indivíduos à aceitação de princípios e de normas sociais necessárias ao fortalecimento de um estado nação, o que se solidifica pela presença de curriculos que condicionam a governança num espaço e tempo determinado (FERREIRA, 2005). É neste contexto que se confunde a escola com a educação! 
Na busca pela superação da (con)fusão que habita, não somente, o que se refere ao ideário da educação, mas aos sentidos hegenônico atribuídos à escola é que Dewey vai defender a educação como necessidade da vida e a escola enquanto a instituição que permite os processos de ensino, de "aquisição dos bons hábiros de pensar" (DEWEY, 1979, p. 179). Nessa linha de pensamento Teixeira (2007), Cavaliere (2014), Moll (2012), entre outros estudiosos da educação em tempo integral defendem essa politica educativa nas suas mais diversas formas de manifestação e modalidades em cujo horizonte, segundo os autores, recai a possibilidade de formação humana ${ }^{4}$.

Nesse cenário, e na busca por conhecer quais sentidos são atribuídos à educação em tempo integral no Estado do Rio Grande do Sul - RS vem sendo realizada, desde o ano de 2018, uma investigação denominada [título subtraído pra fins de sumissão do artigo] numa parceria entre duas universidades, uma brasileira e outra portuguesa, respectivamente, [nomes subtraídos pra fins de sumissão do artigo] ${ }^{5}$. O objeto da pesquisa é a construção de conceitos alternativos de educação integral a partir de práticas que conjugam a educação escolar e não escolar nas perspectivas da formação integral e do desenvolvimento social das comunidades de entorno de escolas.

Deste modo, a investigação que busca compreender a formação integral no âmbito da dinâmica do desenvolvimento social o faz, a partir, do reconhecimento de diversos atores (gestores, professores, crianças e adolescentes e familiares), colocando em circulação dados históricos, socioeconômicos, manifestações culturais, características territoriais, entre outros. Entre os objetivos específicos destacamos: a necessidade de compreender os diferentes significados atribuídos aos conceitos de educação integral, educação em tempo integral, escola em tempo integral, educação integrada e formação integral; a relevância de analisar as dinâmicas presentes nos conceitos, pontos de intersecção e de divergências, enquanto estratégias que ampliam o tempo de permanência de crianças e adolescentes em atividades educativas que conjugam a educação escolar e não escolar; a importância de identificar nas práticas de programas/projetos socioeducativos, de educação integrada e escolas de tempo integral dimensões da setorialidade/intersetorialidade que tendam a consolidar um conceito de educação com vistas ao território/cidade educadora6 ${ }^{6}$

Trata-se de um estudo cuja metodologia está amparada nos pressupostos da pesquisa Educação Comprada, na perspectiva de Nóvoa e Ferreira, com característica intranacional, que estuda experiências de quatro escolas públicas, das redes municipal e estadual, que atuam na perspectiva da educação em tempo integral. As escolas estão situadas no estado do Rio Grande do Sul, localizadas nas regiões: metropolitana de Porto Alegre (2), serra gaúcha (1) e alto uruguai (1). Possuem modalidade de educação integral compreendida pela oferta de tempo integral e/ ou curriculo integral, afiansados pelo sistema educativo oficial ou pela presença de parcerias com organizações governamentais e não governamentais, através de atividades complementares, por meio de programas como o Novo Mais Educação e outras modaliddes de projetos socioeducativos. 
Assim, a pesquisa Educação Comparada enquanto metodologia da investigação intenta elucidar novas questões através de uma aprendizagem compreensiva. Nela o conhecimento existente, anteriormente produzido e dado por inúmeros estudos, quando associado a métodos e técnicas de investigação permite identificar, mais que resultados fragmentados, o desenvolvimento de capacidades de elucidação de dinâmicas educativas. Isto porque em educação nada pode ser explicado por si só, afirma Ferreira (2014).

Para o fim de exemplificar o uso da Educação Comparada na investigação em curso descrevemos, de forma breve, o uso metodológico que fazemos dela. A primeira fase, a pré-descritiva, tem sido a de buscar, em profundidade, dados secundários referentes aos campos empíricos, entre eles: origem, população, história social, indicadores econômicos e de trabalho, recursos de redes socioassistenciais existentes nos municípios e nos bairros onde se situam as escolas, indicadores de violência, saúde, educação, existência e uso de espaços socioeducativos, manifestações culturais. Todos os dados são relativos ao município e ao bairro onde se situa a escola. Assim, busca-se desde o princípio por conhecer as condições materiais existentes nos territórios onde as experiências em questão ocorrem. Trata-se, como afirma Ferreira (2014, p. 225) em "projetar a luz capaz de melhor ver a natureza dos elementos constitutivos e dos discursos sobre os mesmos"

Nesta fase os dados já são comparados na perspectiva bairro/cidade e bairros entre si - no caso das duas cidades da região metropolitana cujos territórios fazem divisa geográfica. Procura-se, neste sentido, conhecer o território (SANTOS, 2012) e o território educativo (DIMENSTEIN, 2004) proporcionadores de aprendizagens a serem difundidas entre todos e todas. Esta centralidade conferida ao território, é dada pelo seu forte caráter educador [ou não] ${ }^{7}$ que pode fazer emergir desenvolvimento social, oriundo da coerência entre as dimensões tempo e espeço (CORDEIRO, ALCOFORADO, FERREIRA, 2011/2012).

Seguimos com a investigação no âmbito das escolas e nas instituições parceiras na ampliação da jornada escolar. São marcadores fundamentais: a origem e a história das instituições, trajetórias, projetos políticos-pedagógicos, formação do público alvo, inserção e impacto nos territórios, colaboração na rede de proteção da cidade, produção de eventos inovadores no âmbito das instituições, identificação de processos de participação em diferentes níveis.

Na segunda fase, a descritiva, é possível construir novas hipóteses buscando pelo impacto da escola no desenvolvimento local $^{8}$ através da relação de indicadores, entre eles, expectativa de vida, socioeconômicos, de aproveitamento escolar considerando, inclusive, as avaliações de larga escola, como o Índice de Desenvolvimento da Escola Básica - Ideb, por exemplo.

Nas escolas, nos Centros de Referência de Assistência Social - CRAS, nos projetos 
sociais, a coleta de dados primários será realizada através de entrevistas semiestruturas de tipo dialogada (MORIN, 1997) e, posteriormente, com a organização de grupos de discussão (MEINERZ, 2011). Ambos os instrumentos terão como sujeitos de pesquisa os professores, gestores, educandos atuais e egressos, familiares e/ou responsáveis.

No momento de submissão desse artigo um roteiro básico das entrevistas está sendo finalizado. Sua estrutura considera, menos os conceitos que advém de concepções do campo teórico e, mais os resultados da primeira fase da investigação que se encontra na análise das comparações iniciais. A exemplo: o lugar da escola no território em termos de desenvolvimento social, aspectos inovadores nas instituições observadas, relação da escola com a rede de proteção na perspectiva da intersetorialidade, aproveitamento escolar de alunos de educação de tempo integral e os de turno único em uma mesma escola, concepções de direitos humanos presentes nos documentos orientadores das escolas, indicadores de violência na relação bairro/ município e continuidade dos estudos em níveis mais avançados, relação entre usuários do Programa Bolsa Família e participação nas entidades assistenciais do bairro e, especialmente, na escola, entre outros. Estes são alguns dos indicadores que necessitam ser compreendidos, associando-os ao já apresentados na seção anterior ${ }^{9}$. Assim que transformados em orientadores na formulação do roteiro das entrevistas permitem a continuidade da investigação.

Desde a fase pré-descritiva os procedimentos analíticos se fazem presentes e evocam a análise de conteúdo, a compreensão e a interpretação do "campo-objeto" (THOMPSON, 2000, p. 358). Entretanto, se as unidades clássicas da análise de conteúdo - pré-análise e categorização, a exemplo do registro, contexto e organização da análise (FRANCO, PEREIRA E DALLABRIDA, 2009) - são diretivas e finalizadoras, na dinâmica da metodologia da Educação Comparada, as unidades se firmam como corpus da análise.

Nessa modalidade, as unidades tendem a buscar por brechas, descontinuidades, multirreferencialidades, na perspectiva de localizar relevâncias, transformações, visando demostrar como algo se transforma naquilo que realiza. Assim que a pesquisa Educação Comparada na sua perspectiva metodológica parecer produzir resultados pela circularidade, onde as fases se auto complementam. Não há lugar para linearidades, uma vez que um achado investigativo produz uma nova conexão que, por sua vez, possibilita novos achados. É isso que vimos observando na pesquisa em questão e que deverá, a tempo, nos levar à fase comparativa e em direção aos resultados.

No que é possível relatar até aqui, resta apontar para o empenho da equipe da pesquisa. Formada por professores pesquisadores, pesquisadores convidados do Grupo [subtraído para fins de submissão]/CNPq, bolsistas de iniciação científica, aprimoramento científico, mestrandos e doutorandos que, incansavelmente, vem realizando o trabalho de coleta de dados, comparações, sobretudo, participando de grupos de estudos sobre a pesquisa Educação Comparada. Todas as atividades, desde 2018, têm sido realizadas num 
cronograma que prevê a internacionalização, publicações em periódicos e a organização de livros, além da abertura da nova fase investigativa.

\section{A guisa de Considerações Finais}

É impossível concluir um estudo de revisão bibliográfica sobre um tema complexo que se apresenta para muitos de nós como sendo pouco conhecido e, principalmente, considerando o alinhamento a Ferreira (2014, p. 227) quando afirma que "o resultado de exercício comparativo acaba por devolver aos outros um outro [e] tudo irá bem se o diálogo recomeçar".

Deste modo, entre os Outros da pesquisa [título subtraído para fins de submissão] vem se produzindo um feliz encontro entre pesquisadores do Brasil e de Portugal e seus interesses de estudos em comum. Nesta conjunção e, a partir dela, na necessidade de adentrar em universos particulares, em estudos já realizados, em concepções de certo modo consolidadas, mesmo assim, vê-se ressalvado o compromisso com a educação em suas mais diversas manifestações.

Assim, é o conceito de educação em sentido amplo, o desejo de compreender o que é educativo num campo de práticas, o que se afirma como sendo educação em tempo integral ou o que se apresenta como propostas de educação integrada é o que nos permite adentrar o universo da Educação Comparada. Mais do que acenar positivamente ao cenário da pesquisa brasileira em educação e sua demanda por internacionalização, também ajuizada pelos órgãos de fomento e confirmada através de parcerias entre universidades, a investigação em curso é a prova de que a pesquisa científica demanda por colaboração.

Deste modo o Outro da Educação Comparada se traduz, também, nos encontros entre tantos Outros que habitam a pesquisa em educação. Deste modo, não é tendencioso afirmar que o Outro da Educação Comparada é, também, e principalmente, a história de uma educação que precisa ser ressignificada para as demandas dos dias de hoje. Sem o equívoco de buscar na história a divisão entre os bons e os maus, o certo e o errado, exemplos de experiências educativas como o da Escola Parque de Anísio Teixeira, podem iluminar o que hoje buscamos compreender ao que se oferece como educação em tempo integral no Brasil e no Rio Grande do Sul, de modo particular.

Ainda quanto a investigação em curso, a Educação Comparada demanda o exercício da transparência a partir do ponto de vista do observador. Assim que 'dentro e fora' de um grupo social significa para Ferreira (2014) e Schriewer (2018) dar visibilidade aos procedimentos de investigação, descrever criticamente as informações, os dados, apresentando as formas de análise e o raciocínio na busca pela substância, pela alteridade, pelas reconstruções de contextos socio-históricos. Nesse sentido, pesquisas Educação comparada buscam elucidar "as relações espaciais, as interdependências com outros 
sectores da sociedade, a situação e as implicações da evolução histórica, as possibilidades e exigências tecnológicas, a dimensão da consciência e da mobilização ideológica" (FERREIRA, 2008, p. 124) sugerindo que, ao se cruzarem dados e metodologias, centro e periferia se encontram.

Para finalizar, alertar que a leitura deste artigo não significa a apropriação do conjunto de estudos realizados por Ferreira e Nóvoa sobre a Educação Comparada, e sequer poder afirmar que não haja desilusões com o uso de pesquisa Educação Comparada, conforme anuncia Nóvoa (2017). Resta reiterar que há, inclusive, outros autores que se destacam nesse campo de estudos, alguns vem citados na Introdução. Eles coincidem na vertente compreensiva e na abordagem de temas correlatos, entre eles, a internacionalização e o desenvolvimento social enquanto duas áreas de interesse da educação contemporânea.

\section{Referências}

AGAMBEN, G. Profanações. São Paulo: Boitempo, 2007.

ARENDT, H. A Condição Humana. Rio de Janeiro: Forense Universitária, 1995.

CAVALIERE, A. M. Escola pública em tempo integral no Brasil: ou política de Estado? Educação \& Sociedade (impresso). V.35, p 1205-1222, 2014.

CORDEIRO, A. M. R.; ALCOFORADO, L.; FERREIRA, A. G. Projeto Educativo Local. Um processo associado a estratégias de desenvolvimento integrado e sustentável. Cadernos de Geografia no 30/31. Coimbra. 2011/2012.

DELEUZE, G. Os Intercessores. In: ____. Conversações. São Paulo: Ed. 34, 1992. p. 151-168.

DEWEY, J. Democracia e Educação. São Paulo: Educação Nacional, 1979.

. Arte como experiência. SP: Fontes Martins, 2019.

DIMENSTEIN, G. Aprendizes de Aprendiz-A descoberta de um foco. In: Cidade Escola Aprendiz, 2004. Disponível em: http://www.sociedadesemear.org.br/arquivos/20111024162406_cartilha_ conexao_aprendiz.pdf Acesso em: 30 de julho de 2019.

FERREIRA, A. G. O sentido da Educação Comparada: uma compreensão dobre a construção de uma identidade. Educação, Porto Alegre, v.31, n.2, p. 124-138, maio/ago.2008.

Os outros como condição de aprendizagem: desafios para uma abordagem sociodinâmica da Educação Comparada. Educação Unisinos 18(3), p. 220-227, set./dez. 2014. doi: 10.4013/edu.2014.183.01

A difusão da escola e a afirmação da sociedade burguesa. Revista Brasileira de História da Educação. $n^{\circ} 9$ jan./jun. 2005. Disponivel em: http://periodicos.uem.br/ojs/index.php/rbhe/ article/view/38660/20191 Acesso em: 13 de julho de 2017. 
FRAGA, N. S. O método da Educação Comparada. 2018. Disponível em:

http://www3.uma.pt/nunosilvafraga/wp-content/uploads/2008/01/o-mtodo-da-educaocomparada.pdf Acesso em 06 de junho de 2019.

FRANCO, J. E.; PEREIRA, H. M.; DALLABRIDA, N. Para uma histórica comparada da Educação. Entrevista com o Professor António Nóvoa. Revista Linhas. Florianópolis. V.10, n. 01, p. 3-15. Jan./jun.2009. Disponível em: http://www.revistas.udesc.br/index.php/linhas/article/ view/1821/1400 Acesso em: 13 de maio de 2019.

FREIRE, P. Pedagogia da Autonomia. SP: Paz e Terra, 1979.

Pedagogia do Oprimido. SP: Paz e Terra, 1993.

INOJOSA, R. M. Sinergia em Políticas e Serviços Públicos: Desenvolvimento Social com Intersetorialidade. Cadernos FUNDAP. n.22, p.102-110, 2001

ITALIA. Carta das cidades educadoras. Disponível em: http://www.edcities.org/redeportuguesa/wp-content/uploads/sites/12/2018/09/Carta-das-cidades-educadoras.pdf Acesso em: 27 de julho de 2019.

LÉVINAS, E. Entre nós: ensaios sobre a alteridade. Petrópolis: Vozes, 2005.

MEINERZ, C. Grupos de Discussão: uma opção metodológica na pesquisa em educação. Educação e Realidade. v. 26, n.2, 2011. p. 485 - 504.

MOLL, J. et al. Caminhos da educação integral no Brasil: direito a outros tempos e espaços educativos. Porto Alegre: Penso, 2012. p. 129-46.

MORIN, E. Sociologia. Lisboa: Publicações Europa-America, 1997.

MOURA, E. ; ZUCCHETTI, D. T. . A dimensão educativa da educação não escolar: tem sentido este debate? Revista Educação (PUCRS. ONLINE), v. 42, p. 150-158, 2019. DOI: http://dx.doi. org/10.15448/1981-2582.2019.1.27950

NÓVOA, A. Ilusões e Desilusões da Educação Comparada. Política e Conhecimento. (s.a) 2017 Disponível em: https://www.fpce.up.pt/ciie/sites/default/files/ESC51_Antonio.pdf Acesso em: 13 de maio de 2019.

; CATANI, D. B. Estudos Comparados sobre a Escola: Portugal e Brasil (séculos XIX e XX). Anais do I Congresso Brasileira da História da Educação. 2000. Disponível em: http://www. sbhe.org.br/novo/congressos/cbhe1/anais/028_antonio_denice.pdf Acesso em: 15 de maio de 2019.

SANTOS, M. Pensando o espaço do Homem. São Paulo: Editora da USP, 2012.

SHRIEWER, J. Pesquisa em educação comparadas sob condições de interconectividade global. São Leopoldo: Oikos, 2018.

TEIXEIRA, A. Educação não é privilégio. São Paulo: Editora Nacional, 1971.

THOMPSON, J. B. Ideologia na cultura moderna: teoria crítica na era dos meios de comunicação de massa. Petrópolis: Vozes, 2000. 
TROMBETA, S.; TROMBETA, L. C. Inacabamento. STRECK, D. et all (orgs.). Dicionário Paulo Freire. Belo Horizonte: Autentica, 2008.

ZUCCHETTI, D. T.; FERREIRA, A. G. Da escola de tempo integral à educação integral: as circunstâncias e o ideal do desenvolvimento humano. In: SEVERO, L. R. de L.; POSSEBON, E. G. (orgs.). Fundamentos e Temas e Pedagogia Social e Educação Não Escolar. João Pessoa: Editora da UFPb, 2019.

Contato para correspondência: Dinora Tereza Zucchetti. E-mail: dinora@feevale.br 
1 O documento resulta da revisão de conjunto de ideias desenvolvidas no $61^{\circ}$ Congresso da Comparative and Internacional Camparative Socity, proferida em Atlanta (EUA) no ano de 2017.

2 As concepções de sociologia de Durkhein e sua noção de sociedade são fundamentais para os avanços da Educação Comparada na perspectiva da elaboração de uma metodologia das Ciências Sociais que consiste em estabelecer relações entre relações ou padrões inteiros de relações (SCHIEWER, 2018).

3 Estas relações já são questões que emergem da pesquisa que será apresentada na seção seguinte, neste texto.

$4 \quad$ Entre as difetentes modalidade existem escolas de educação integral que possuem curriculo integral, outras, oferecem modalidades de oficinas socioeducativas no contraturno, outras o fazem em parceria associando-se, formalmente ou não, a outras instituições de carater socioassistencial.

5 Trata-se de uma investigação que prevê, inicialmente, colaboração institucional. Num segundo momento, a pesquisa será estendida à realidade portuguesa onde será realizada coleta e comparação de dados entre os dois países.

6 Há importantes conceitos presentes nos objetivos específicos da investigação, contudo, não é central neste artigo o aprofundamento deles. Segue, contudo, algumas referências de bibliografias utilizadas pela autora para os termos: educação não escolar (MOURA E ZUCCHETTI, 2019); Educação em tempo integral, escola em tempo integral, educação integrada e formação integral (MOLL, 2012), Intersetorialidade (INOJOSA, 2001) e Cidade Educadora (2004).

7 Grifo da autora.

8 O desenvolvimento local como o compreendemos para o estudo se dá a partir de Cordeiro, Alcoforado e Cordeiro (2011/2012). Para os autores o desenvolvimento local é também desenvolvimento social, integrador de todas as pessoas e, principalmente, sustentável enquanto campo de domínio da educação num determinado território - unidade geográfica e identidade cultural -, porquanto que não se reduz a simples dimensão econômica, mas também social e cultural.

$9 \quad$ Ver nota no 2. 